\title{
FOTOGRAFÍA, NARRACIÓN Y REFLEXIVIDAD. A PROPÓSITO DE LA REEDICIÓN DE PODRÍA SER YO. LOS SECTORES POPULARES URBANOS EN IMAGEN Y PALABRA
}

\section{Ramiro Segura ${ }^{1}$}

En el año 2018, con motivo de cumplirse los 30 años de su publicación original en 1987, una edición conjunta de Asunción Casa Editora y el Instituto de Desarrollo Económico y Social (IDES) relanzó Podría ser yo. Los sectores populares urbanos en imagen y palabra de Elizabeth Jelin y Pablo Vila, con fotografías de Alicia D’Amico. La edición facsimilar de un libro originalísimo y difícil de encasillar en el panorama de las ciencias sociales y de la fotografía artística de la Argentina de los primeros años del retorno de la democracia es en sí mismo algo para celebrar. Todo lo cual se potencia debido a que la edición facsimilar viene acompañada de otro libro, un libro sobre el libro, que se propone como un modo de continuar el diálogo iniciado 30 años antes y que reflexivamente involucra las voces de los propios autores (Jelin y Vila) como la lectura crítica del libro original, tanto desde la ciencias sociales como desde la fotografía. Esta es, entonces, una reseña múltiple: de un libro paradigmático de las ciencias sociales argentinas; de un libro sobre el libro que contiene lecturas críticas y ejercicios reflexivos sobre el mismo; de las lecturas posibles que se abren desde el presente sobre el libro y sobre el libro del libro; y de las derivas que las fotos, las palabras y los textos nos permiten pensar sobre el lugar de la imagen en la investigación social contemporánea.

Comencemos por el libro que motiva todo esto. Podría ser yo. Los sectores populares urbanos en imagen y palabra es sin lugar a dudas una aventura innovadora y desafiante: lo era hace más de 30 años cuando fue publicado por primera vez y lo es también hoy. El libro condensa los resultados de una investigación sobre la vida cotidiana de los sectores populares de Buenos Aires en los primeros años del retorno de la democracia construida a partir de la fotografía. Los sociólogos (Jelin y Vila) propusieron un conjunto de temas sobre la vida cotidiana de los sectores populares urbanos (barrio, trabajo, servicios, tiempo libre,

\footnotetext{
${ }^{1}$ Universidad Nacional de San Martín e Universidad Nacional de La Plata, Argentina.

Email: segura.ramiro@gmail.com.

Orcid ID: orcid.org/0000-0001-6482-3514
} 
familia, religiosidad, calle, etc.) y una reconocida fotógrafa argentina ( $\mathrm{D}^{\prime}$ Amico) tomó alrededor de 700 fotografías en Buenos Aires y el Gran Buenos Aires, atenta a registrar la diversidad de actores (varones y mujeres; niños, adultos y ancianos) y de relaciones sociales (solidaridad, conflicto, jerarquía e igualdad) presentes en el mundo popular. Las fotos fueron agrupadas por temas y se realizaron 50 reuniones colectivas en organizaciones políticas, centros comunitarios, sociedades de fomento, lugares de trabajo y casas particulares, donde personas de los sectores populares dialogaron a partir de las fotografías. En estas entrevistas grupales los participantes seleccionaron las fotografías y las organizaron según sus propios criterios; discutieron con las imágenes y propusieron tomar otras fotografías; reflexionaron sobre su vida cotidiana; y se identificaron o tomaron distancia respecto de lo que veían en las fotografías.

El producto final del itinerario de un diálogo, como con precisión lo llaman Jelin y Vila en la breve introducción, uno de los dos momentos (junto con las conclusiones) en que los autores toman la palabra, es un libro podríamos describir a partir de la idea de montaje de categorías, imágenes y palabras que se produjeron, circularon y se discutieron durante ese largo diálogo polifónico. La tarea de escucha y de registro de estos intercambios colectivos a partir de las fotografías por parte de los investigadores condujo a la selección de las categorías, las imágenes y los testimonios que componen la mayor parte del libro, cuyo borrador circuló entre muchas de las personas que participaron de los encuentros, dando lugar a una nueva instancia de diálogo en la cual se realizaron críticas y sugerencias sobre imágenes que faltaban y que se incorporaron a la versión publicada.

El libro es un objeto muy bello, con un creativo diseño en el que se intercalan 132 fotografías en blanco y negro reproducidas en el mismo tamaño $(10 \times 15 \mathrm{~cm})$ que tenían las fotos en los encuentros colectivos y fragmentos de las reflexiones y los testimonios que las imágenes generaron en esos encuentros, acercándonos como lectores a esa experiencia de mirar y dialogar. No hay jerarquías en la disposición de las imágenes y las palabras en el libro: las imágenes no ilustran las palabras (no exponen lo que es) ni las palabras explican las imágenes (no dicen lo que es), sino que intercaladas a lo largo del libro abren un espacio ambiguo, de proximidad y de distancia, de (in)adecuación, de diálogo y tensión entre imagen y palabra, desestabilizando las ilusiones de transparencia que solemos atribuirle tanto a la fotografía como a la palabra. 
Las fotos y las palabras están organizadas en 11 capítulos que abordan distintas dimensiones de la vida cotidiana de los sectores populares urbanos. Algunas de las categorías que organizan los capítulos estaban desde el inicio de la investigación y abordan cuestiones como el trabajo ("hay mil formas de ganarse la vida"), las relaciones familiares y de género (“el ocio es de los otros”) y el espacio residencial ("barrios y villas”); otras son emergentes de los propios espacios de diálogo e intercambio, como la espera en tanto experiencia temporal constitutiva de la vida popular ("la resignación de espera"), la esperanza de futuro puesta en los hijos ("nos aferramos a los más chicos”) y las expectativas ambivalentes respecto de las promesas del retorno democrático ("nosotros estamos con la democracia, ella ¿está con nosotros?”). En este sentido, vale destacar que el libro comienza con dos "réplicas" producidas a partir de la circulación del borrador del libro entre varias personas que habían participado de las entrevistas colectivas: mientras en una de las réplicas algunas personas cuestionan el modo en que son representadas, enfatizando que ellas viven en "un barrio" y no en una villa, en la segunda réplica algunas personas entrevistadas señalan que ellas efectivamente viven en "una villa", avanzando en una dinámica de identificación y de distanciamiento que atraviesa todo el libro y que se capta de manera sutil con el tiempo condicional del título: podría ser yo. En suma, las fotos constituyeron un estímulo a partir del cual las personas conversaron sobre lo que se veía en la foto, sobre sí mismas y las demás, sobre la realidad que vivían y sus causas, y sobre los significados que todo esto tenía para cada una de ellas. Como se señala en las conclusiones, el libro no sugiere la existencia de un sujeto colectivo unitario y homogéneo, de contornos nítidos, sino más bien una dinámica de identidad y diferencia, de mismidad y otredad, que atraviesa la vida cotidiana de los heterogéneos sectores populares urbanos.

Si la fotografía, el diálogo y el montaje condensan el proceso de producción de Podría ser yo, el libro sobre el libro nos sitúa ante la reflexividad, la temporalidad y la recursividad: reflexionar sobre lo que nos enseña una investigación realizada hace treinta años que, como señala Agustina Triquell en la introducción, estableció un cruce entre el campo del arte y las ciencias sociales y muestra caminos a seguir para investigación social creativa y rigurosa; indagar sobre las temporalidades pasadas, presentes y futuras involucradas en el acto mirar las imágenes desde el presente; y habilitar un ejercicio de derivas y de imaginar devenires que coloca a las imágenes en una espiral de sentido que no cesa de desplegarse. 
El libro sobre el libro, dedicado a la memoria de Alicia D'Amico (1933-2001), se organiza en dos partes de tres capítulos cada una, en una edición muy bella y con un diseño en el que se intercalan entre los capítulos montajes de imágenes de la investigación y de la recepción del libro. La primera parte, "Reflexiones críticas”, abre con el capítulo “¿Veinte años no es nada? (volver sobre) fotografías de la cotidianeidad popular en los ochenta" donde, entre otros ejercicios, Jelin y Vila revisitan una sociedad de fomento que formó parte de los lugares en los que se tomaron fotografías y se realizaron entrevistas grupales. A partir del análisis de un reencuentro cargado de recuerdos y emociones, muestran el juego de temporalidades que el ejercicio dispara: revisitar los imaginarios sobre el propio pasado, reflexionar sobre las esperanzas incumplidas, y reelaborar la historia del barrio y de sus organizaciones. Siguen a este capítulo dos ejercicios críticos: uno desde el campo de la fotografía y el otro desde las ciencias sociales. En "Inflexiones estéticas y pantallas discursivas: El lugar de Podría ser yo en la producción de Alicia D'Amico", Francisco Medial y Juan Cruz Pedroni cuestionan la estabilización de la obra de D’Amico en torno a la idea de fotografía humanista. Si bien su celebrado trabajo con Sara Facio entre 1960 y 1985 concuerda con tal caracterización, los autores muestran que su desarrollo posterior (habitualmente excluido por la crítica artística) cuestiona la autonomía de la fotografía como arte al abrir un espacio en el que, como sucede en Podría ser yo, no solo se reparte la voz sobre las fotografías sino que se encuentran, dialogan y se interpelan recíprocamente la fotografía y las ciencias sociales. Se trata, en definitiva, de un desplazamiento de la fotografía como obra (cerrada) de denuncia a la fotografía como medio (abierto) para desplegar una estrategia de auto-narración que D’Amico comenzó a explorar con los talleres fotográficos feministas. En este sentido, lo que concluyen los autores sobre las fotografías de D'Amico puede ser extensivo a todo el libro: descentramiento de la posición autoral, en tanto la fotografía es el acto inicial de una secuencia más amplia orientada a crear un espacio provisorio para lo común. Por su parte, en "Nosotros y los "otros" capturados por la luz fotográfica" Ludmila Da Silva Catela reconstruye la larga historia de vinculación entre fotografía y ciencias sociales, situando a Podría ser yo en esa genealogía más amplia de relaciones entre la mismidad y la alteridad a través de la fotografía. En esta dirección, la autora destaca que las fotografías son objetos con los cuales las personas 
hacen cosas y, por lo mismo, más que su significación interna, deberían interesarnos las experiencias y los usos que las fotografías arrastran como objeto.

La segunda parte del libro sobre el libro, "Reflexiones en primera persona", se compone de intervenciones de Jelin y Vila sobre los significados del libro para sus propios aprendizajes y trayectorias académicas. En "Una foto robada" Pablo Vila relata una hermosa historia sobre una de las fotografías de Alicia D'Amico. Al poco tiempo de iniciadas las entrevistas se evidenció que había fotografías que las personas elegían de manera recurrente para hacer sus comentarios. Entre ellas había una que él denominó "la foto metodológica", porque daba pie a dos relatos antagónicos sobre la pobreza (pobreza con dignidad y pobreza sin dignidad). La presencia de unas manchas en la foto fue el motivo por el cual Alicia D’Amico, contra la opinión de los autores, se negó a que integrara la publicación. Lo que D’Amico nunca supo fue que esa foto acompañó a Vila durante toda su trayectoria posterior, incluso en la evaluación de su proyecto doctoral donde defendió una metodología similar a la de Podría ser yo para la investigación que desarrolló en la frontera entre Estados Unidos y México. Por su parte, en “Gente y fotos. Una mirada personal” Elizabeth Jelin relata la historia que siguió a la publicación de Podría ser yo: su distribución gratuita en organizaciones e instituciones que trabajaban con sectores populares, las exposiciones fotográficas seguidas de debates en espacios tan diversos como el Centro Cultural Recoleta y un barrio periférico de una localidad del interior del país, las reuniones en diversas instituciones del Gran Buenos Aires para reflexionar sobre el libro. Su amplia y heterogénea difusión dio lugar a lecturas heterogéneas y contrapuestas, que incluyeron cuestionamientos por parte de profesionales y militantes que trabajaban en barrios populares. El texto de Jelin es un ejercicio de memoria sobre el trabajo más querido de su vasta trayectoria y sobre los modos en que fue leído en la Argentina de los años 80, sobre los límites de lo decible y lo pensable en los primeros años de retorno democrático, y sobre las formas en que prefiguró su agenda de trabajo subsiguiente en torno a género, derechos humanos y memoria. Por último, el libro finaliza con la entrevista "30 años después", realizada por Sergio Caggiano a Jelin y Vila, donde relatan la trastienda del libro y sus implicaciones personales con el proyecto: la creación de Lugar de Mujer a finales de la dictadura, espacio de encuentro de mujeres donde D'Amico fotografió a Jelin como parte de sus exploraciones sobre la belleza femenina; la convocatoria de Jelin a un joven Vila 
para que se sumara a la investigación que terminaría en Podría ser yo; las reflexiones y los aprendizajes en torno a la imagen, el diálogo y la escucha en la investigación social; las reacciones de los colegas y las discusiones sobre el mundo popular y sobre la Argentina que el libro motorizó; las continuidades y los cambios en los sectores populares urbanos desde su realización hasta el presente; entre otras cuestiones de la espiral de sentido que su reedición suscita.

En síntesis, la reedición del libro original y el estudio crítico que lo acompaña componen una obra dialógica y reflexiva ineludible que permite, al menos, tres lecturas transversales a ambos volúmenes: le lectura epistemológica sobre el estatuto de la imagen y la palabra en la investigación social; la lectura metodológica sobre el trabajo con fotografías como vía de acceso a las dinámicas de la vida social; y la lectura sustantiva acerca de las persistencias y las transformaciones de la sociedad argentina contemporánea y de los modos en que las ciencias sociales se embarcaron en su comprensión en las últimas décadas.

Queda abierta la invitación, la pregunta y el desafío que lanza Jelin para la investigación por venir:

Hay algo más, sin embargo. El horizonte de futuro se abre, para seguir en esta espiral que vuelve sobre lo hecho, ampliándolo y multiplicándolo. En los tiempos de teléfonos celulares y selfies, de Facebook e Instagram, la imagen captada es un fluir, con más sentido de comunicación cotidiana y permanente que de preservación, y eso abre una gran pregunta que, como toda gran pregunta, deja abierta su respuesta, ¿cómo sería un proyecto como Podría ser yo entrado el siglo XXI? (Jelin, 2018: $89)$.

Una obra como la reseñada aquí brinda pistas sólidas para avanzar en esta exploración futura sobre las relaciones entre imagen, palabra y vida social.

Recebido: 29/05/2020

Aprovado: 04/09/2020 